\title{
Spread of False News Stories on Facebook: An Assessment of Credibility Cues and Personality
}

Lacie Geary

Follow this and additional works at: https://researchrepository.wvu.edu/etd

\section{Recommended Citation}

Geary, Lacie, "Spread of False News Stories on Facebook: An Assessment of Credibility Cues and Personality" (2017). Graduate Theses, Dissertations, and Problem Reports. 5654.

https://researchrepository.wvu.edu/etd/5654

This Thesis is protected by copyright and/or related rights. It has been brought to you by the The Research Repository @ WVU with permission from the rights-holder(s). You are free to use this Thesis in any way that is permitted by the copyright and related rights legislation that applies to your use. For other uses you must obtain permission from the rights-holder(s) directly, unless additional rights are indicated by a Creative Commons license in the record and/ or on the work itself. This Thesis has been accepted for inclusion in WVU Graduate Theses, Dissertations, and Problem Reports collection by an authorized administrator of The Research Repository @ WVU. For more information, please contact researchrepository@mail.wvu.edu. 


\title{
Spread of False News Stories on Facebook: An Assessment of Credibility Cues and Personality
}

\author{
Lacie Geary
}

\author{
Thesis submitted \\ to the Reed College of Media \\ at West Virginia University \\ in partial fulfillment of the requirements for the degree of \\ Master of Science in Journalism
}

Diana Martinelli, Ph.D., Chair

Steve Urbanski, Ph.D.

Julia Fraustino, Ph.D.

Elizabeth Cohen, Ph.D.

Department of Journalism

Morgantown, West Virginia

2017

Keywords: Social Media, Credibility, Personality Behaviors

Copyright 2017 Lacie Geary 


\section{ABSTRACT \\ Spread of False News Stories on Facebook: An Assessment of Credibility Cues and Personality}

\section{Lacie Geary}

This study used a 2 x 2 method to examine the effectiveness of credibility cues on Facebook and how the personality traits neuroticism and openness impact sharing behaviors across cues of different shapes and colors. Findings suggested the color red increased cue noticeability, however, overall a low number of participants noticed any of the four varying cues across conditions, indicating that the fast-paced scrolling nature of online mediums prevents users from noticing credibility cues. Future research should examine the differences in pace of scrolling and information intake across different generations. This information might be useful to media outlets to help identify what credibility cues are most effective across target markets online. 


\section{TABLE OF CONTENTS}

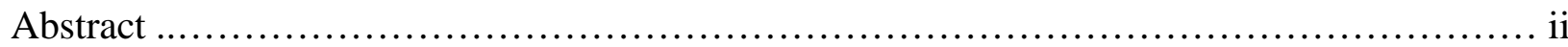

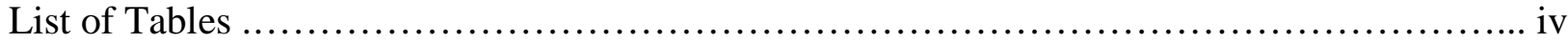

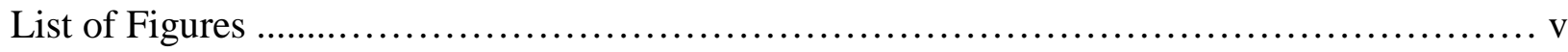

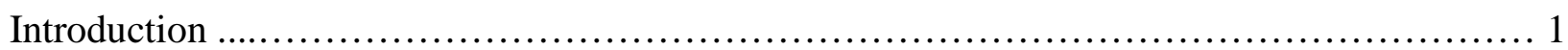

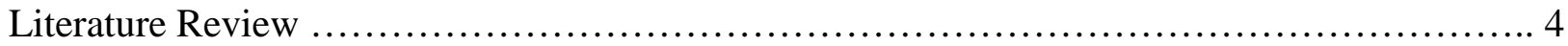

Research Questions .............................................................. 7

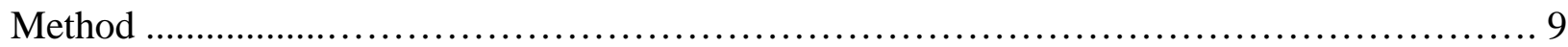

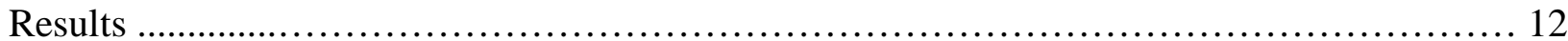

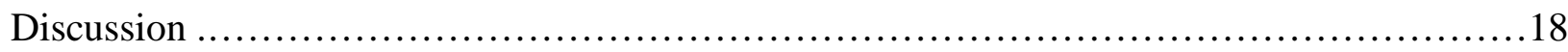

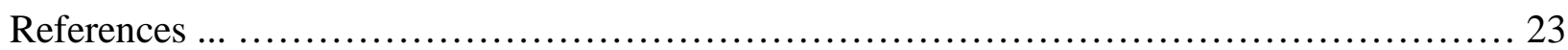

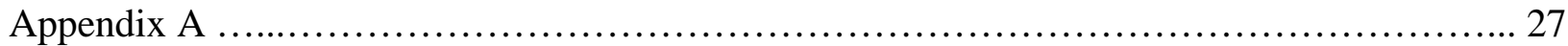

Appendix B ................................................................. 29

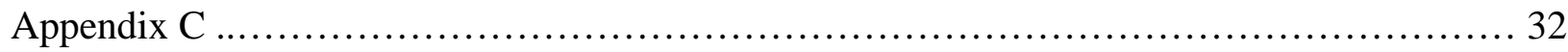

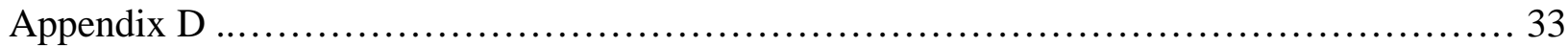




\section{List of Tables}

Table 1 ........................................................................ 10

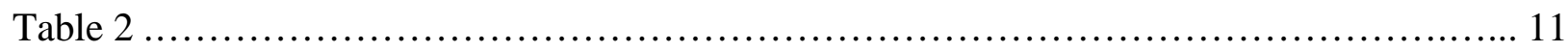

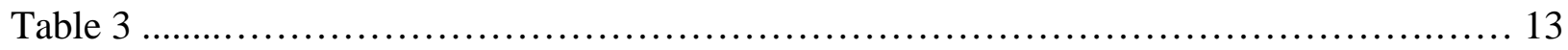

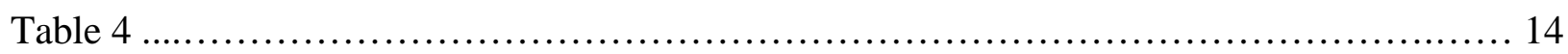

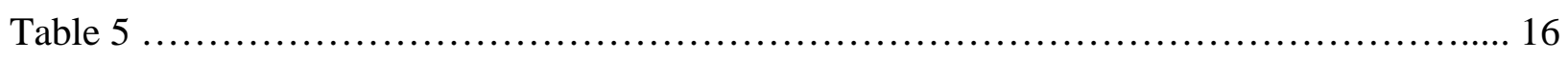

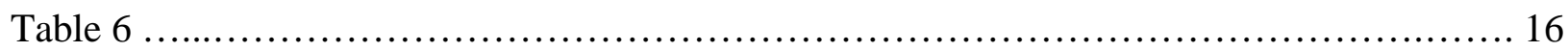

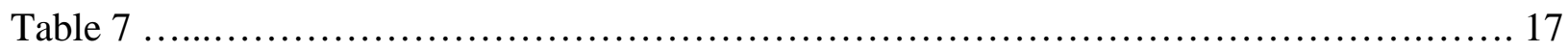

Table 8 ......................................................................... 17 


\section{List of Figures}

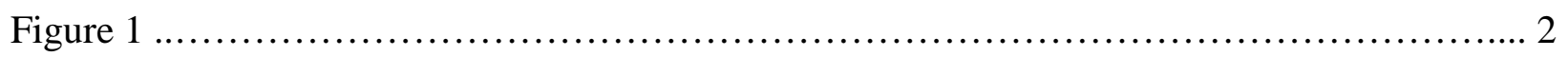

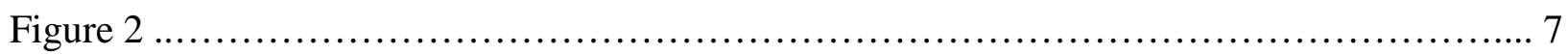

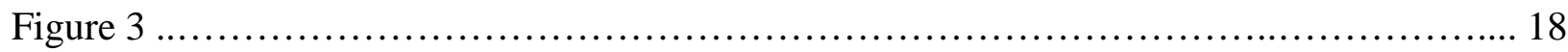




\section{INTRODUCTION}

The spread of false or misleading news stories on Facebook has become a seemingly unstoppable problem in today’s society. The shift from print to digital media news disseminators has created new credibility assessment issues, leaving many consumers unable to decipher legitimate from illegitimate news stories. In the pre-digital era, journalism organizations largely controlled original reporting, writing, production and delivery, making audience evaluation of credibility easier. Over time, technological companies such as Facebook and Apple have become more dominant players in the news product arenas, whether they intended to be or not (Mitchell, \& Holcomb, 2016). Currently, 62\% of U.S. adults get their news from social media sites (Mitchell, \& Holcomb, 2016); 44\% of them through Facebook (Gottfried \& Shearer, 2016). This statistic, along with a reported 1.71 billion monthly active users in the second quarter of 2016, establishes Facebook as the largest distributor of information in the world (Statista, 2016).

This transition has caused credibility confusion among social media users, leading to the viral spread of false and misleading news stories across social media outlets. The Pew Research Center found nearly two thirds of U.S. adults believe fabricated news stories cause large amounts of confusion, a perception shared across many demographics (Barthel, Mitchell \& Holcomb, 2016). As a result, many professional fact-checking sites have been created in an effort to provide guidance. Snopes.com has been a top online fact checker for over 20 years, and has been featured in The Washington Post, New York Times, The Wall Street Journal, and more (2016). Fil Menczer, a professor at Indiana University specializing in the spread of misinformation stated, "These things [news posts] are very hard to detect automatically if they are true or not. Even professional fact-checkers can’t keep up.” According to Menczer’s research, 13 hours stand 
between the publication of a false report and debunking, allowing enough time for false reports to spread to millions (Solon, 2016).

Facebook officials reported negative feedback from users over the amount of misleading news stories found in their feeds and their request to view fewer of them (Owens, 2015). In

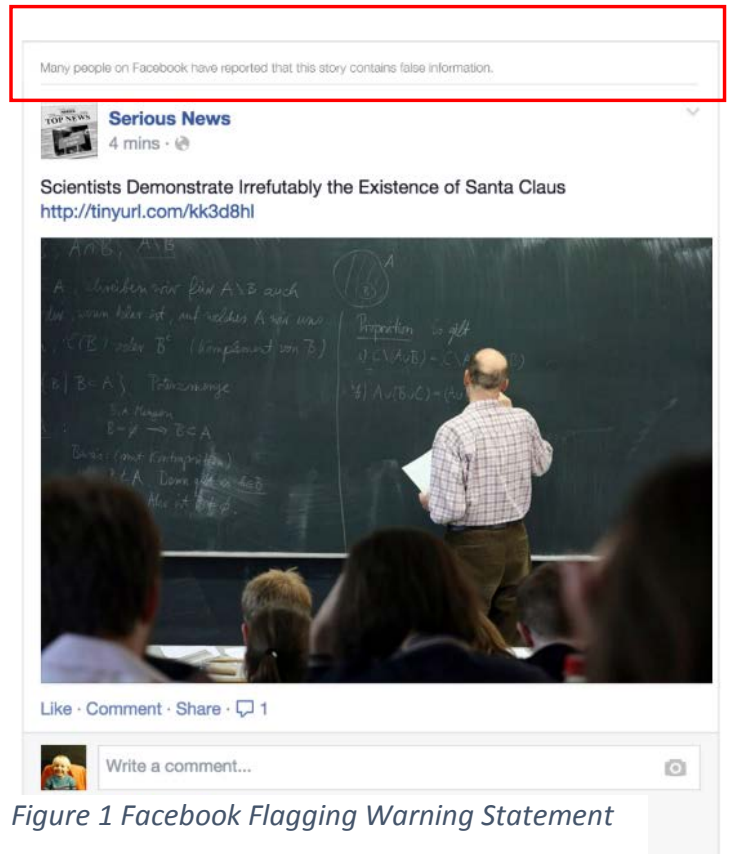
January 2015, Facebook addressed the misleading news story problem by introducing a new feature called "flagging”. This feature allows users to report a story they see in their News Feed as false. Posts that receive a high number of flaggings will be marked with the warning "Many people on Facebook have reported that this story contains false information,” as shown in the red box of Figure 1. However, given the small, grey physical appearance of the warning message, there is concern as to whether the warning will be a noticeable enough credibility cue to be effective in deterring users from sharing.

Studying ways to combat the spread of false or misleading news on digital landscapes is important for many reasons. The World Economic Forum named the spread of misinformation on social media as one of the top global risks in 2013, stating:

Social media increasingly allows information to spread around the world at breakneck speed. While the benefits of this are obvious and well documented, our hyper connected world could also enable the rapid viral spread of information that is either intentionally or unintentionally misleading or provocative, with serious consequences (p. 23).

Recent studies on the role Facebook played in the 2016 U.S. presidential election brought the spread of false information into more light. According to an analysis of thousands of 
postings, links and documents by cybersecurity company, FireEye Inc, Russia used social media as a weapon to influence perceptions about the U.S. election by promoting misleading narratives in the Republican nominee's favor (Strohm, 2016). PropOrNot, a nonpartisan collection of researchers with foreign policy, military and technology backgrounds, estimates that stories planted or promoted by Russia’s disinformation campaign were viewed more than 213 million times (Timberg, 2016). On November 12, Facebook CEO Mark Zuckerberg addressed the uproar of Facebook's role in the election, insisting that less than one percent of its content is classified as fake news and hoaxes. However, the quantity of fake news on Facebook isn't important; the number of people who share it is (Romano, 2016). The Washington Post conducted a 2016 study from Aug. 31 to Sept. 22, 2016, analyzing four different Facebook accounts and the news stories that trended across each. They uncovered five trending stories that were indisputably fake and profoundly inaccurate, including a tabloid story claiming that the Sept. 11 terrorist attacks were a “controlled demolition” (Ingram, 2016).

Credibility is the foundation of people's interactions and democratic expression and choice. As the world becomes more connected, it is vital for people to understand the perils of the new media environment and learn how to assess credibility (Metzger \& Flanagin, 2008). Assessing the effectiveness of Facebook's warning message, while testing the effectiveness of an alternative warning message, can lead to future recommendations for more effective credibility cues on digital landscapes. Researching psychological personality traits and their correlation to spreading information labeled as unverified anticipates a future problem past the credibility assessment stage, and can give recommendations for the study of forthcoming credibility issues. 


\section{LITERATURE REVIEW}

\section{Credibility}

As almost all information is now disseminated online, several traditional credibility cues have been removed through disintermediation, a process that provides an end consumer with direct access to information that would otherwise require a mediator such as a newspaper. This has forced individuals to evaluate vast amounts of online information on their own; making it tougher to distinguish between reliable and misleading news stories (Eysenbach, 2008). Whereas credibility has traditionally been tied to an authority-based approach, users now have to determine credibility through multiple judgments using heuristic strategies (Metzger \& Flanagin, 2008, p 106). Heuristic strategies rely on rapid examination of credibility cues, focusing on information’s surface characteristics (Flanagin \& Metzger, 2010). Because Facebook is an open forum, surface characteristics, such as the source of a post, can be misleading due to fake Facebook news accounts and fake news websites.

Media professor of Merrimack College, Melissa Zimdars, compiled 58 of the largest “fake, false, or regularly misleading websites” that purposefully publish fake information or are unreliable. This list included websites such as MSNBC.website, AmericanNews.com and Abcnews.com.co (2016). Due to the misleading surface characteristics of the domain name, careful assessment of credibility is required to determine misinformation on Facebook. However, many studies have shown a correlation between personality and sharing behavior on social media, and certain personalities may perceive credibility cues differently. 


\section{Personality and Social Media Sharing Behavior}

Among social media literature, many studies conducted on information sharing included personality traits as predictors (Amichai-Hamburger \& Vinitzky, 2010; Ross et al., 2009). A study conducted by Xinran Chen of Nanyang Technological University analyzed users’ misinformation sharing on social media and its correlation with personality traits among 171 university student participants. The study found that personality was an influential role in sharing misinformation. Neuroticism, characterized by anxiety, fear, worry, envy, jealousy, and loneliness, had a significant negative influence on sharing misinformation. Ross et al. (2009) found higher neuroticism to be linked to Facebook use as means to seek attention and social support that could be lacking from their physical lives. For more neurotic people, sharing doubtful information on social media may lead to negative consequences, such as being judged for sharing false information, which increases anxiety and apprehension (Chen, 2016). Engaging in such emotional disclosure activities as venting has also been linked to neuroticism (Seidman, 2013).

Openness, characterized by curiosity and open-mindedness, has been linked to using Facebook for finding and disseminating information over using it for socializing (Hughes et al., 2012). Chen (2016) found that openness had a positive influence on users’ sharing, and that open people share more misinformation to explore its novel ideas even if it contradicts scientific views. This research aligns with Heinström’s (2003) findings that open people tend to welcome new and challenging information. Ross et al. (2009) found more open people use Facebook as a sociability function, and open people may share misinformation to start conversations or to spur interaction with friends (Chen, 2016). 
Agreeableness, characterized as sympathetic and considerate, was found to be negatively associated with using Facebook to seek attention, and positively associated with using Facebook to communicate and connect with others (Seidman, 2013). As each personality trait is associated with using and sharing information on Facebook in various ways, the Big Five Inventory Test, a widely used personality assessment that evaluates openness, conscientiousness, extraversion, agreeableness, and neuroticism will allow for analysis of personality traits and sharing misinformation. This test, found in Appendix A, has been used in many studies to assess the correlation between personalities and online behaviors.

\section{Facebook Flagging Cue: Color Psychology \& Digital Scrolling}

The impact colors have on people has produced mixed research results. Research has indicated that elements such as personal preference, experiences, upbringing, cultural differences, context, etc., can potentially muddy the effects that color has on individuals (Ciotti, 2014). However, several studies on the color red have shown the color elicits more of a response, indicating that the color tends to affect perspiration, brain waves, blood pressure, pulse and respiration (Birren, 1984).

Colors have been consistently labeled with certain characteristics for marketing and branding purposes. The color red has shown to be salient and strong, while the color gray is presented as weak and passive (Adams \& Osgood, 1973). Gray is known as the color of conformism and is usually an unresponsive color, unattached, neutral and impartial (Color Psychology, 2016). Because the color red produces a stronger response than the color gray, it may provide for a better cue response for warning labels on digital, scrolling platforms. 
The color of Facebook’s warning label isn’t the only feature that makes it potentially unnoticeable; the small size of the warning statement text also makes it hard to see. Additionally, many societies such as the U.S., associate the color red with "stop" as it is the color of stop signs and stop lights. There is a gap in provided research on how scrolling on digital social media platforms affects elements’ noticeability from information overload and scanning. The flagging feature's small, grey appearance may not be as noticed on a fast-paced, scrolling platform as a red warning label box would be. This research may lend some insight as to what aspects are more prone to being noticed or unnoticed on mobile, scrolling platforms.

\footnotetext{
[1.7) Filming Cops 12 ill Like Page Can we address this now? Help SPREAD THE WORD because there is a MEDIA BLACK OUT on this story!

Police Shoot 6-Year-Old Boy in the Head Multiple Times Killing Him In breaking news, another tragic incident of police murder has just occurred over
night, leaving a 6 -year-old boy dead. The shooting took place in Marksville,... COUNTERCURRENTNEWS COM

Figure 2 Red "Unverified" warning label

One of the main purposes of this study is to identify whether the physical appearance of the warning message will be an effective credibility cue, and if the warning message would be more effective with a red "unverified" label as shown in Figure 2. Identifying if there is a personality correlation with sharing misinformation and the detection between two credibility cues on Facebook can lend to future recommendations for enhancing credibility cues on media platforms to help prevent the spread of misinformation.
}

\section{RESEARCH QUESTIONS}

In some cases, credibility confusion related to digital media may fuel the spread of false or misleading information across social media platforms. Labeled as one of the world's top risks in 2013, the worldwide problem has made research to assess, diagnose and provide solutions to the spread of false information on social media a priority. Because of the research on social media sharing behaviors and credibility cues noted in the literature review above, the following 
hypotheses and their rationales were formulated for this study, which tests the effectiveness of two different message warnings on likely sharing behavior:

Because the Facebook warning statement is in gray type and is relatively small,

H1: Facebook's new warning statement is not a noticeable enough cue to affect viewers' credibility perception of a news article.

Independent variable: Facebook’s flagging warning

Dependent variable: Credibility perception

Because larger type and the color red are more noticeable,

H2: The red “unverified” labels will affect viewers' credibility perceptions of a Facebook news article.

Independent variable: Red flagging warning

Dependent variable: Credibility perception

Decause people who score high on neuroticism have been shown to be less likely to share Facebook news stories owing to concerns about credibility,

H3: $\quad$ People who score high on neuroticism will be less likely to share a Facebook news story that has the red unverified label than the one with the Facebook warning statement.

Independent variable: Neuroticism score

Dependent variable: Likely sharing behavior 
Because people who score high on openness have been shown to be more likely to share Facebook news stories, regardless of their accuracy,

H4: $\quad$ People who score high on openness will be equally likely to share a Facebook news story across both warning conditions.

Independent variable: Openness score

Dependent variable: Likely sharing behavior

\section{METHOD}

In this study, the term "fake news," was carefully avoided owing to its potential emotional charge from its repetitive use in political news and commentary. Instead, the term "false news" was used throughout. To test the research questions, a 2 (flagging warning statement: Facebook's and Snopes.com) x 2 (gray and red versions) between-subjects design was used for this experiment. The five-minute Big Five Inventory test was given in the form of an online survey first to assess participants' levels of neuroticism and openness. For the 2x2 design, participants were randomly assigned to one of four conditions involving experimenter-generated mobile Facebook timelines, and asked to click the one news post they would be most likely to share, if any. There was an answer choice for participants to select if they were not likely to share any of the posts. Upon selecting an answer, participants were directed to an online questionnaire where they completed questions drawn from a validated news credibility scale (Flanagin \& Metzger, 2000) about the post, if applicable, as well as Facebook sharing behavior and demographic questions, plus a manipulation check question. (See Appendix B for the complete questionnaire). A pretest of participants was conducted to help identify and address any 
potential confusion or issues prior to the experiment and to gauge about how long the experiment took participants to complete. Changes made as a result of the pretest included instruction edits and integration of the PDF Facebook timeline into the online survey.

More than 140 participants were recruited from College of Media courses to reach the initial goal for this experiment of 100 participants (25 per condition); however, 67 respondents did not follow directions, leaving 80 valid responses. Owing to time constraints and the end of the semester, recruitment ceased and the analysis was conducted with the 80 responses. The students, largely underclassmen, included participants from Generation Z, born in the years 1996 to 2010, who have grown up completely in the tech era and thus were expected to provide valuable insight for testing Facebook sharing behaviors. Of the 80 participants, 31\% were seniors, followed by sophomores (30\%), juniors (24\%), and freshmen (15\%), as shown in Table 1. The average age of participants was 20 years old, as reported in Table 2 . More than $90 \%$ of participants identified as White, with 7.5\% African-American, and < 3\% Asian and Hispanic.

\section{Table 1}

Experiment Participants by Class Rank

\begin{tabular}{|l|l|r|r|}
\hline \multirow{3}{*}{ Valid } & Frequency & Percent & $\begin{array}{c}\text { Valid } \\
\text { Percent }\end{array}$ \\
\hline & Freshmen & 12 & 15.0 \\
\cline { 2 - 4 } & Sophomore & 24 & 30.0 \\
\cline { 2 - 4 } & Junior & 19 & 23.8 \\
\cline { 2 - 4 } & Senior & 25 & 31.3 \\
\cline { 2 - 4 } & Total & 80 & 100.0 \\
\hline
\end{tabular}


Table 2

Experiment Participants by Age

\begin{tabular}{|c|c|c|c|c|c|}
\hline & Ages & Percent & $\begin{array}{l}\text { Valid } \\
\text { Percent }\end{array}$ & $\begin{array}{c}\text { Cumulative } \\
\text { Percent }\end{array}$ & \\
\hline \multirow[t]{6}{*}{ Valid } & 18 & 6 & 7.5 & 8.6 & 8.6 \\
\hline & 19 & 14 & 17.5 & 20.0 & 28.6 \\
\hline & 20 & 18 & 22.5 & 25.7 & 54.3 \\
\hline & 21 & 17 & 21.3 & 24.3 & 78.6 \\
\hline & 22 & 15 & 18.8 & 21.4 & 100.0 \\
\hline & Total & 70 & 87.5 & 100.0 & \\
\hline Missing & System & 10 & 12.5 & & \\
\hline Total & 80 & 100.0 & & & \\
\hline
\end{tabular}

\section{Stimuli Development}

In order to produce a realistic mobile Facebook experience in an experimental setting, experimenter-generated Facebook timelines were created using Adobe InDesign to capture more natural elements of mobile social media behaviors, such as scrolling. (See Appendix C). Because non-negative animal posts that do not include cats or dogs are fairly neutral, false animal news stories from snopes.com were used across all four conditions to help eliminate possible content bias as much as possible. All four timelines used the same made-up news profile (i.e. News Watch 33) to avoid possible confounding recognition bias. Neither a Facebook profile photo of a person, nor likes or shares were included in the timeline to avoid unintended social or credibility bias that could affect likely sharing behavior. 


\section{RESULTS}

To test the reliability of Flanagin \& Metzger’s (2000) credibility index, the bias score was reverse coded for parallel direction of the index, and means were compared across believability, trustworthiness, bias, completeness and accuracy. Overall, the index had moderate reliability $(a=.77)$. A Cronbach's alpha of .70 and above is considered to have reliability (Nunnally \& Bernstein, 1994). However, to try and establish a stronger overall measure of reliability for the credibility construct, completeness and bias were dropped, leaving only accuracy, trustworthiness and believability in the credibility index. This produced a much stronger reliability $(a=.92)$. After identifying the credibility index's reliability, we were able to test hypotheses one and two.

H1: Facebook’s new warning statement is not a noticeable enough cue to affect viewers' credibility perception of a news article.

In order to identify how many participants noticed each of the condition's credibility cues, a dichotomous question asking whether participants noticed the cue or not was followed by a multiple-choice, color-identification manipulation check question. Five participants from the Facebook gray warning statement condition responded that they noticed the cue. But by comparing these results to our manipulation check question, no participant correctly identified the gray warning statement. These results are consistent with H1 that Facebook's new gray warning statement is not a noticeable enough cue to affect viewers' credibility perception of a news article. But, some participants may have color-blindness, which could preclude their correctly identifying the correct color in the manipulation check. However, the overall $\mathrm{N}$ of those who reported noticing the cues at all was small. The use of a red color made a slight, although 
not statistically significant, difference in warning statement detection. The red statement condition was correctly identified by three participants after the manipulation check.

For Facebook's warning statement condition, a t-test was used to compare means of credibility perceptions for participants given Facebook’s new gray warning statement cue and participants given the red warning statement. The results indicated no significant statistical difference between credibility perceptions for the gray statement condition $(M=4.52, S D=1.63)$ and the red statement condition $(M=4.68, S D=.946)$, as shown in Table 3; $t(30.5)=-.39, p=$ .69).

Table 3

Statement Conditions' Credibility Perceptions

\begin{tabular}{|l|l|r|r|r|r|}
\hline & Statement & $\mathrm{N}$ & Mean & $\begin{array}{c}\text { Std. } \\
\text { Deviation }\end{array}$ & $\begin{array}{c}\text { Std. } \\
\text { Error } \\
\text { Mean }\end{array}$ \\
\hline Credibility Index & $\begin{array}{l}\text { Gray } \\
\text { statement }\end{array}$ & 20 & 4.52 & 1.63 & .36 \\
\cline { 2 - 7 } & Red statement & 20 & 4.68 & .94 & .21 \\
\hline
\end{tabular}

H2: The red “unverified” labels will affect viewers’ credibility perceptions of a Facebook news article.

When comparing those who noticed the cues and passed the manipulation check question for the labels, 15\% (3 out of 20) truly noticed the red label within its condition, and one participant truly noticed the gray label within its condition. The credibility perception means of participants who selected a post with the red "unverified" label condition as the post they would be most likely to share and those who did not select a post with the red "unverified" label condition, or selected no post at all, were compared through analysis of variance (ANOVA). 
Under H2, participants who selected a post other than a red "unverified" label post should have expressed a higher credibility perception of the article they selected than those who selected a red "unverified" label post, or those who selected no post at all as one they would be likely to share. The results indicated a slightly higher perception of news article credibility by those who selected a post to share that did not have a red "unverified" label condition compared to those who selected a post with a red "unverified" label condition on it, although the N's were very small ( $n=5$ and 12, respectively), and the differences were not statistically significant across the groups $(M=4.40$ for the unverified condition, $S D=1.96 ; M=4.58, S D=1.66$ for no condition; $M=4.22$ for selecting neither type, $S D=.770$ ), as shown in Table 4 . A one-way ANOVA showed that the effect of label on credibility was not significant: $F(2,17)=.065, p=.937)$.

Table 4

Credibility Perceptions within the Red Label Condition

\begin{tabular}{|l|r|r|r|}
\hline & Mean & \multicolumn{1}{|c|}{ N } & $\begin{array}{c}\text { Std. } \\
\text { Deviation }\end{array}$ \\
\hline Condition & 4.40 & 5 & 1.96 \\
\hline Neither & 4.22 & 3 & .77 \\
\hline No Condition & 4.58 & 12 & 1.66 \\
\hline Total & 4.48 & 20 & 1.58 \\
\hline
\end{tabular}

H3: People who score high on neuroticism will be less likely to share a Facebook news story that has the red unverified label than the one with the Facebook warning statement.

Per the literature, those who scored high for neuroticism were expected to avoid sharing the red "unverified" label posts because research found that for more neurotic people, sharing doubtful information on social media may lead to negative consequences, such as being judged 
for sharing false information, which increases anxiety and apprehension (Chen, 2016). Because of the small physical appearance of the Facebook warning statement, it was expected that participants would not notice the cue and, therefore, would be more likely to share it.

For the Big Five Inventory personality test, questions 2, 6, 8, 9, 12, 18, 21, 23, 24, 27, 31, 34, 35, 37, 41, and 43 were reverse coded per the test's instructions to find participants' neuroticism and openness scores. For the 5-point scale, results were dichotomized into high (4.00 - 5.00) and low (1.00 - 2.99) scores. Respondents whose scores were in the $3.00-3.99$ were categorized as neither high nor low. As predicted in H 3, no participants who scored above a 3.00 on the 5-point scale for neuroticism shared a post with a Snopes red label, as shown in Table 4. Participants who scored higher on neuroticism shared more gray Facebook warning statement posts, as shown in Table 5. Although the difference between high and low neuroticism groups regarding their likelihood to share was not statistically significant, $X^{2}(12, N=20)=17.15, p=$ .144 , the cell counts were fewer than expected and the findings were consistent with the hypothesis that those who scored higher on neuroticism avoided sharing the Snopes red label posts, as more participants who scored higher in neuroticism shared a post with Facebook's gray warning statement on it ( $n=0$ vs. $n=4$, respectively). This may be due to participants not noticing the gray warning statement at all, as also was predicted in this study. 
Table 5

Red “Unverified” Label Post Sharing Behaviors across Neuroticism Scores

\begin{tabular}{|l|r|r|r|r|r|r|r|r|r|r|r|}
\hline $\begin{array}{l}\text { Neuroticism } \\
\text { Score }\end{array}$ & $<2.50$ & 2.75 & 2.88 & 3.00 & 3.13 & 3.63 & 3.88 & 4.13 & 4.25 & 4.50 & \\
\hline $\begin{array}{l}\text { Red label } \\
\text { condition }\end{array}$ & 1 & 1 & 1 & 2 & 0 & 0 & 0 & 0 & 0 & 0 & 5 \\
\hline $\begin{array}{l}\text { No } \\
\text { Condition }\end{array}$ & 2 & 2 & 1 & 1 & 1 & 1 & 1 & 1 & 1 & 1 & 12 \\
\hline Total & 3 & 3 & 2 & 3 & 1 & 1 & 1 & 1 & 1 & 1 & 17 \\
\hline
\end{tabular}

Table 6

Facebook Gray Warning Statement Post Sharing Behaviors across Neuroticism Scores

\begin{tabular}{|l|r|r|r|r|r|r|r|r|r|}
\hline $\begin{array}{l}\text { Neuroticism } \\
\text { Score }\end{array}$ & $<3.25$ & 3.38 & 3.50 & & 4.88 & 4.00 & 4.38 & 4.63 & 4.75 \\
\hline $\begin{array}{l}\text { Gray } \\
\text { statement } \\
\text { Condition }\end{array}$ & 5 & 1 & 1 & 1 & 1 & 1 & 1 & 0 & 11 \\
\hline $\begin{array}{l}\text { No } \\
\text { Condition }\end{array}$ & 1 & 0 & 1 & 0 & 0 & 0 & 0 & 1 & 3 \\
\hline Total & 6 & 1 & 2 & 1 & 1 & 1 & 1 & 1 & 14 \\
\hline
\end{tabular}

H4: People who score high on openness will be equally likely to share a Facebook news story across both warning conditions.

Similarly, respondents’ openness scores were dichotomized into high (4.00 - 5.00) and low $(1.00-2.99)$ scores on a 5-point scale. The majority of the participants tested neither high nor low for openness. Owing to the small number of participants who tested in the high or low ranges (see Table 6), no reliable chi-square results could be obtained to check for statistical differences between the groups. Therefore, the hypothesis could neither be supported nor debunked. 
Table 7

Red “Unverified” Label Post Sharing Behaviors across Openness Scores

\begin{tabular}{|l|l|r|r|r|}
\hline & & Condition & No Condition & Total \\
\hline $\begin{array}{l}\text { Openness } \\
\text { Score }\end{array}$ & Low & 1 & 3 & 4 \\
\cline { 2 - 6 } & High & 1 & 0 & 1 \\
\hline Total & & 2 & 3 & 5 \\
\hline
\end{tabular}

\section{Sharing Motivations}

Using Chen’s (2016) sharing motivations question to identify why participants might share news that may not be credible, more than 50\% $(n=43)$ identified "It is interesting” as a reason why they may share news stories that lack credibility. An interesting result of this question is that $10 \%(n=8)$ chose "Comes from close family and friends" and $7.5 \%(n=6)$ chose "Comes from authoritative sources" as reasons why they would share news otherwise seen as lacking in credibility (See Table 7). Overall, participants found each of the four Facebook timelines (News Watch 33) to be slightly credible, regardless of the warning presented there $\left(M_{\text {greystatement }}=4.52 ; M_{\text {redlabel }}=4.58\right)$, even though $94 \%(\mathrm{~N}=75)$ responded that they had never heard of the made-up news source.

Table 8

Sharing Motivations

\begin{tabular}{|l|r|r|}
\hline \multicolumn{1}{|c|}{ Sharing Motivations } & N & Percent \\
\hline Interesting & 43 & 54 \\
\hline Comes from close family and friends & 8 & 10 \\
\hline Comes from authoritative sources & 5 & 6 \\
\hline
\end{tabular}

*Participants were able to select more than one answer 


\section{Descriptive Results}

To gather more detailed results, participants were asked to qualitatively indicate if they found the news post they shared credible or not credible, and what factors would influence them to share the posts. Out of 52 clear-cut responses, 38\% $(\mathrm{N}=20)$ found the posts to be credible, $27 \%(\mathrm{~N}=14)$ found them to be lacking in credibility, and 35\% ( $\mathrm{N}=18)$ identified the content of the post as an influencing factor in their perception.

\section{DISCUSSION}

\section{Implications}

The purpose of this study was to explore different credibility cues on Facebook and how personality traits affect identifying and reacting to credibility cues in an effort to help understand the spread of false news stories. Although not statistically supported, the results imply some information. For example, no participants correctly identified the gray Facebook warning statement, three correctly identified the red warning statement; one participant correctly identified the Snopes gray label, and three correctly identified the red Snopes label. These results are consistent with the intended predictions of $\mathrm{H} 1$ and $\mathrm{H} 2$, and may indicate that a color change from gray to red made a difference in participants noticing the cue. This also may suggest that size does not have as much of an impact on noticing the cue as initially perceived, for the red label was significantly larger than the warning statements and did not produce higher Ns. However, because a very low percentage of participants noticed the cues overall, this may indicate that the fast-paced scrolling of Generation Z prevents them from noticing any type of warning.

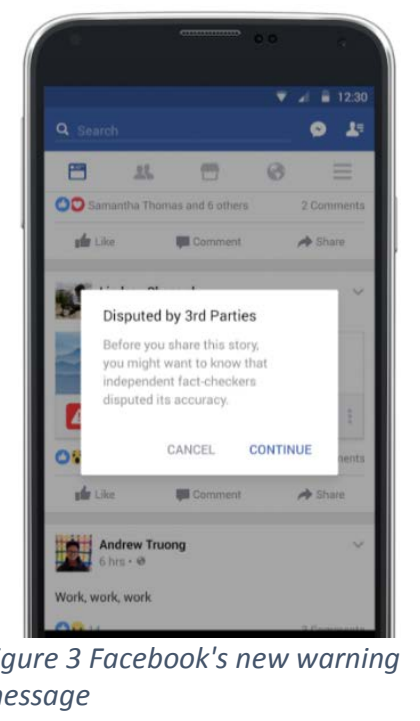


Facebook may have found similar results due to a large change in their false news warning messages in 2017, for they later added a pop-up window that alerts users that a post's accuracy has been disputed when they attempt to share it. This is shown in Figure 3 (Mosseri, 2016).

When comparing means between conditions and credibility perceptions, no significant statistical differences were identified. However, a larger sample may have produced significant results, as small Ns can preclude the discovery of small effects (Fleishman, 2012). With a larger sample, results may have supported H2, whereby participants within the red "unverified" label condition who did not select a red label post to share would have a higher credibility perception mean than those who selected a red label post. The same problem of small Ns applies to testing levels of neuroticism and openness and their effects on sharing behaviors. A larger number of participants, which likely would have produced more variance, may have produced statistically significant differences. With the given results, H3 was not supported statistically, but results did show no participant who scored higher than 3.00 for neuroticism shared a post with a red label. This is as expected, given that participants with high neuroticism scores are less likely to share posts lacking credibility to avoid negative social consequences (Chen, 2016).

Although source evaluation is noted as an important aspect of media literacy and credibility perceptions by Facebook (Price, 2017), this study's results imply that source was not important to the participants. Participants identified "It is interesting" as the top reason why they may share news stories that lack credibility. Fewer than $10 \%$ chose source-based options "[The news] comes from close family and friends" and "[The news] comes from authoritative sources" as reasons why they would share news lacking in credibility. This may suggest that the content of the news carries more weight in why Facebook users share information than its source does, perhaps owing to the platform's more "social," and thus less serious, tone. Adding to this 
experiment's implications for sources, participants found the Facebook fictitious timelines slightly credible, although 94\% had never heard of the news source before. This statistic can be problematic for many reasons, particularly because participants included journalism undergraduate students who belong to Generation Z. This might indicate low media literacy overall, blind trust in any source that resembles legitimacy, or a simple lack of concern for source, accuracy and credibility.

If this study is replicated in the future, it is suggested that a split be added in the survey to send participants who do not score high or low in neuroticism and openness in the personality test out of the survey. Although this would require a larger number of participants, it would allow for better testing of personality's effect on sharing behaviors. Because only a small number of participants noticed any of this study's cues, more research on information intake and fastpaced scrolling on social media platforms such as Facebook should be pursued. For example, future studies might test differences in pace of scrolling and information intake across different generations. This information might be useful to media outlets to help identify what credibility cues are most effective to what target markets online. Further research is also recommended for the news credibility index (Flanagin, \& Metzger, 2000) used in this study. An index that has been widely used for nearly two decades may need to be revisited as a news credibility index in the era of social and mobile media to ensure it remains relevant and reliable. Other studies might explore what young people know about the spread of false news and its dangers within a democratic society.

\section{Limitations}

Some limitations should be considered when interpreting the results. The participants were not necessarily representative of the larger population, as they were recruited through 
College of Media classes and word-of-mouth. Therefore, although the experiment used random assignment, more varied--and larger numbers of--participants may have produced different results. Of the 80 participants, few scored high or low on openness and neuroticism, creating small cell sizes that could not be reliably statistically compared. Although the sharing motivations question was referenced from prior published research (Chen, 2016) way the question was worded may have influenced the responses received, and limited the number of participants who selected source credibility as a reason why they would share. (Question 4, Appendix B). Finally, the Big Five Inventory Personality test included a 5-point scale, whereas a 7-point scale may have produced more nuanced results for statistical analysis. In addition, it is possible that some participants may have been color blind, which could have ameliorated differences between the gray and red conditions.

In conclusion, this study identified that Facebook's gray warning statement introduced in 2015 is not a noticeable enough cue to affect users' news credibility perceptions. By testing the warning against the color red and a label format, this study showed that color had more of an influence than shape in noticeability. A relatively low noticeability rate across all cues lends to a greater potential problem with fast-paced scrolling and cues on social media. However, Facebook has recently identified and addressed this issue by changing their gray 2015 warning statement to a new pop-up window in 2017. This should increase user noticeability and cue effectiveness. Source was found to have little weight in this study in terms of perceived credibility perception, lending support for the need for more media literacy education. Personality was found to have no statistical significance in credibility perceptions, but the sample sizes compared were too small to accurately draw conclusions. 
Given that the fast-paced nature of today's news consumption and participants’ rapid decisions to share will likely continue to grow, media literacy and the ramifications of carelessness should be part of our citizens’ general education systems. Alerting young minds to the importance of responsibilities associated with information sharing seems necessary to help ensure an informed, educated democracy and to help safeguard the reputations of legitimate media outlets. 


\section{References}

(2013). Global Risks Report. World Economic Forum, p. 23. Retrieved from http://www3.weforum.org/docs/WEF_GlobalRisks_Report_2013.pdf

(2016). About snopes.com. Snopes. Retrieved from http://www.snopes.com/info/aboutus.asp

(2016). Grey. Color Psychology. Retrieved from http://www.colorpsychology.org/gray/

Adams, F., \& Osgood, C. (1973). A Cross-Cultural Study of the Affective Meanings of Color. Journal of Cross-Cultural Psychology, 4(2), 135-156. doi:

$10.1177 / 002202217300400201$

Barthel, M., Mitchell, A., \& Holcomb, J. (2016). Many Americans Believe Fake News Is Sowing Confusion. Pew Research Center. Retrieved from http://www.journalism.org/2016/12/15/many-americans-believe-fake-news-is-sowingconfusion/

Birren, F., (1984). Color \& Human Response: Aspects of Light and Color Bearing on the Reactions of Living Things and the Welfare of Human Beings, 44.

Chen, X., (2016). The influences of personality and motivation on the sharing of misinformation on social media. iSchools. Retrieved from https://www.ideals.illinois.edu/bitstream/handle/2142/89327/Chen145.pdf?sequence=1

Ciotti, G., (2014). Color Psychology: How Colors Influence the Mind. Psychology Today. Retrieved from https://www.psychologytoday.com/blog/habits-not-hacks/201408/colorpsychology-how-colors-influence-the-mind

Correa, T., Hinsley, A. W., \& de Zuniga, H. G. (2010). Who interacts on the Web? The intersection of users’ personality and social media use. Computers in Human Behavior, 26, 247-253. 
Eysenbach, G. (2008). Credibility of health information and digital media: new perspective and implications for youth. M.J. Metzger, A.J. Flanagin (Eds.), Digital Media, Youth, and Credibility, MIT Press, Cambridge, MA, pp. 123-154

Flanagin, A. J., \& Metzger, M. J. (2000). Perceptions of Internet information credibility. Journalism \& Mass Communication Quarterly, 77(3), 515-540.

Fleishman, A. (2012). Significant p-values in Small Samples. Allen Fleishman Bio Statistics. Retrieved from allenfleihmanbiostatistics.com

Gottfried, J., \& Shearer, E., (2016). News Use Across Social Media Platforms 2016. Pew Research Center. Retrieved from http://www.journalism.org/2016/05/26/news-useacross-social-media-platforms-2016/

Hughes, D. J., Rowe, M., Batey, M., \& Lee, A. (2012). A tale of two sites: Twitter vs. Facebook and the personality predictors of social media usage. Computers in Human Behavior, 28, 561-569.

Ingram, M., (2016). Facebook Still Has a Fake News Problem. The Washington Post. Retrieved from http://fortune.com/2016/10/12/facebook-fake-news/

John, O. P., Naumann, L. P., \& Soto, C. J. (2008). Paradigm Shift to the Integrative Big-Five Trait Taxonomy: History, Measurement, and Conceptual Issues. In O. P. John, R. W. Robins, \& L. A. Pervin (Eds.), Handbook of personality: Theory and research (pp. 114158). New York, NY: Guilford Press.

Lee, C., \& Ma, L., (2012). News sharing in social media: The effect of gratifications and prior experience. Computers in Human Behavior, 28(2), 331-339. http://dx.doi.org/10.1016/j.chb.2011.10.002

Metzer, M. J., \& Flanagin, A. J., (2008). Digital Media, Youth and, Credibility. The MIT Press, 
Cambridge Massachusetts

Mitchell, A. Holcomb, J. (2016). State of the News Media 2016. Pew Research Center. Retrieved from http://www.journalism.org/2016/06/15/state-of-the-news-media-2016/

Mosseri, A. (2016). News Feed FYI: Addressing Hoaxes and Fake News. Facebook. Retrieved from https://newsroom.fb.com/news/2016/12/news-feed-fyi-addressing-hoaxes-and-fakenews/

Nunnally JC, Bernstein I. Psychometric theory. 3rd ed. McGraw-Hill; New York: 1994.

Owens, E., (2015). News Feed FYI: Showing Fewer Hoaxes. Facebook Newsroom. Retrieved from http://newsroom.fb.com/news/2015/01/news-feed-fyi-showing-fewer-hoaxes/

Price, R. (2017). Facebook will now teach you how to spot false news. Business Insider. Retrieved from http://www.businessinsider.com/facebook-how-to-spot-fake-news-2017-4

Romano, A., (2016). The scariest part of Facebook's fake news problem: fake news is more viral than real news. Vox Media. Retrieved from http://www.vox.com/2016/11/16/13626318/viral-fake-news-on-facebook

Ross, C., Orr, E. S., Sisic, M., Arseneault, J. M., Simmering, M. G., \& Orr, R. (2009). Personality and motivations associated with Facebook use. Computers in Human Behavior, 25, 578-586.

Schwarz, N. (2004). Metacognitive experiences in consumer judgment and decision making. Journal of Consumer Psychology, 14(4), 332-348.

Seidman, G. (2013). Self-presentation and belonging on Facebook: How personality influences social media use and motivations. Personality and Individual Differences, 54, 402-407. Solon, O., (2016). Facebook's failure: did fake news and polarized politics get Trump elected? 
The Guardian. Retrieved from

https://www.theguardian.com/technology/2016/nov/10/facebook-fake-news-electionconspiracy-theories

Strohm, C. (2016). Russia Weaponized Social Media in U.S. Election, FireEye Says. Bloomberg. Retrieved from https://www.bloomberg.com/news/articles/2016-1201/russia-weaponized-social-media-in-u-s-election-fireeye-says

Timberg, C. (2016). Russian propaganda effort helped spread 'fake news' during election, experts say. The Washington Post. Retrieved from https://www.washingtonpost.com/business/economy/russian-propaganda-effort-helpedspread-fake-news-during-election-experts-say/2016/11/24/793903b6-8a40-4ca9-b712716af66098fe_story.html

Xu, Q. (2013). Social recommendations, source credibility, and recency effects of news cues in a social bookmarking website. Journalism and Mass Communication Quarterly, 90(4), 757-775.

Zimdar, M. (2016). My 'fake news list' went viral. But made-up stories are only part of the problem. The Washington Post. Retrieved from https://www.washingtonpost.com/posteverything/wp/2016/11/18/my-fake-news-listwent-viral-but-made-up-stories-are-only-part-of-the-problem/?utm_term=.b02acc4c9e58 


\section{Appendix A: Big Five Personality Test}

\section{How $I$ am in general}

Here are a number of characteristics that may or may not apply to you. For example, do you agree that you are someone who likes to spend time with others? Please write a number next to each statement to indicate the extent to which you agree or disagree with that statement.

\begin{tabular}{|c|c|c|c|c|}
\hline $\mathbf{1}$ & $\mathbf{2}$ & $\mathbf{3}$ & $\mathbf{4}$ & $\mathbf{5}$ \\
$\begin{array}{c}\text { Disagree } \\
\text { Strongly }\end{array}$ & $\begin{array}{c}\text { Disagree } \\
\text { a little }\end{array}$ & $\begin{array}{c}\text { Neither agree } \\
\text { nor disagree }\end{array}$ & $\begin{array}{c}\text { Agree } \\
\text { a little }\end{array}$ & strongly \\
\hline
\end{tabular}

\section{I am someone who...}

1. Is talkative

2.

3.

4.

5.

6.

7.

8.

9.

10. Is curious about many different things

11. Is full of energy

12. St__ Starts quarrels with others

13. Is a reliable worker

14. Can be tense

15. Is ingenious, a deep thinker

16. Generates a lot of enthusiasm

17. Has a forgiving nature

18. Tends to be disorganized

19. Worries a lot
20. Has an active imagination

21. Tends to be quiet

22. Is generally trusting

23. Tends to be lazy

24 Is emotionally stable, not easily upset

25. Is inventive

26. Has an assertive personality

27. Can be cold and aloof

28. Perseveres until the task is finished

29. Can be moody

30. Values artistic, aesthetic experiences

31. Is sometimes shy, inhibited

32. Is considerate and kind to almost everyone

33. Does things efficiently

34. Remains calm in tense situations

35. Prefers work that is routine

36. Is outgoing, sociable

37. Is sometimes rude to others

38. Makes plans and follows through with them 
39. Gets nervous easily

40. Likes to reflect, play with ideas

41. Has few artistic interests

42. Likes to cooperate with others

43. Is easily distracted

44. Is sophisticated in art, music, or literature 


\section{Appendix B}

\section{Questionnaire}

1. Please indicate the degree to which the post you just saw is Not at all

\section{Extremely}

$\begin{array}{llllllll}\text { Believable } & 1 & 2 & 3 & 4 & 5 & 6 & 7 \\ \text { Accurate } & 1 & 2 & 3 & 4 & 5 & 6 & 7 \\ \text { Trustworthy } & 1 & 2 & 3 & 4 & 5 & 6 & 7 \\ \text { Biased [R] } & 1 & 2 & 3 & 4 & 5 & 6 & 7 \\ \text { Complete } & 1 & 2 & 3 & 4 & 5 & 6 & 7\end{array}$

2. Did you find the news post credible/not-credible or somewhere in between? In other words, what factors influenced you?

3. Have you ever heard of the news source "News Watch 33”?

Yes

No

4. For the following statements, please check any and all that apply as to why you might occasionally share news stories that may not be credible and accurate. [referenced from Chen study]

It can be a good topic for conversation.

It is interesting.

It is new and eye-catching.

It is fun.

It is current.

It provides understanding of particular event or situation. 
It seems useful.

It seems important.

It comes from my close friends or family.

It is consistent with my belief or assumption.

It seems accurate.

It comes from authoritative sources.

It looks frightening.

5. Some Facebook news stories may have shown a warning label or statement. Did you notice any warning label or statement with the news stories you saw?

Yes

No

Unsure

6. If so, what color was the warning statement?

Yellow

Blue

Red

Gray

Green

7. What is your age?

18

19

20

21

22

23 \& up 
8. What is your class?

Freshmen (less than 29 credit hours)

Sophomore (29-58 credit hours)

Junior (59-88 credit hours)

Senior (89 or more credit hours)

9. What is your ethnicity?

African American

Asian

Hispanic

Pacific Islander

White 


\section{Appendix C}

\section{Generated Facebook Timeline}
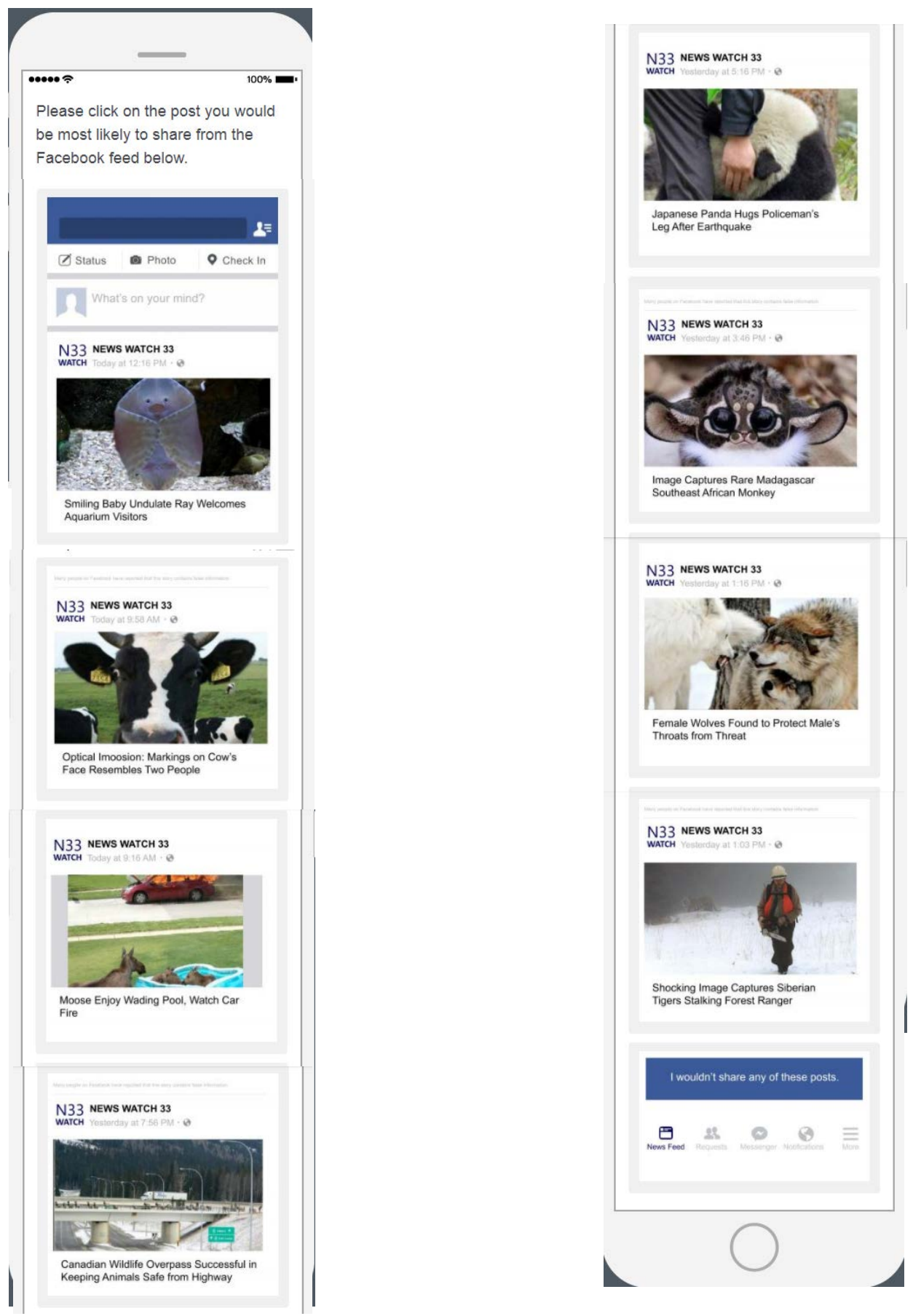


\title{
West VurginiaUniversity. \\ Office of Research Integrity and Compliance \\ 886 CHESNUT RIDGE ROAD MORGANTOWN, WV 26506
}

\section{Acknowledgement Letter Exempt Initial Protocol Review}

\author{
Action Date \\ $04 / 12 / 2017$ \\ To \\ Diana Martinelli \\ From \\ WVU Office of Research Integrity and Compliance \\ Approval Date \\ $04 / 12 / 2017$ \\ Expiration Date \\ $04 / 11 / 2020$ \\ Subject \\ Acknowledgement Letter Exempt Initial Protocol Review \\ Protocol Number \\ 1702480423 \\ Title \\ Spread of False News Stories on Facebook: An Assessment of Credibility Cues \\ and Personality
}

The above-referenced study was reviewed by the West Virginia University Institutional Review Board IRB and was granted exemption in accordance with 45 CFR 46.101.

- This research study was granted an exemption because the Research involves educational tests, survey procedures, interview procedures or observation of public behavior and (i) information obtained is recorded in such a manner that human subjects cannot be identified, directly or through identifiers linked to the subjects; and (ii) any disclosure of the human subjects responses outside the research could not reasonably place the subjects at risk of criminal or civil liability or be damaging to the subjects financial standing, employability, or reputation [45 CFR 46.101(2)]. All exemptions are only good for three years. If this research extends more than three years beyond the approved date, then the researcher will have to request another exemption. The following documents have been acknowledged for use in this study and are available in the WVU+kc system:

Documents reviewed and/or approved as part of this submission:

Survey Part 2.docx: 2017-02-26-05:00

Feed 1.pdf: 2017-02-26-05:00

Feed 2.pdf: 2017-02-26-05:00

Feed 3.pdf: 2017-02-26-05:00 
Feed 4.pdf: 2017-02-26-05:00

Survey Part 1.docx: 2017-02-26-05:00

Lacie Geary Cover Letter.pdf: 2017-02-27-05:00

Documents for use in this study have been acknowledged and are available in the WVUkc system in the Notes and Attachments section of your protocol.

The Office of Research Integrity and Compliance is here to provide assistance to you from the initial submission of an IRB protocol and all subsequent activity. Please feel free to contact us by phone at 304.293.7073 with any question you may have. Thank you.

WVU Office of Research Integrity and Compliance

Date:04/12/2017

Signed:

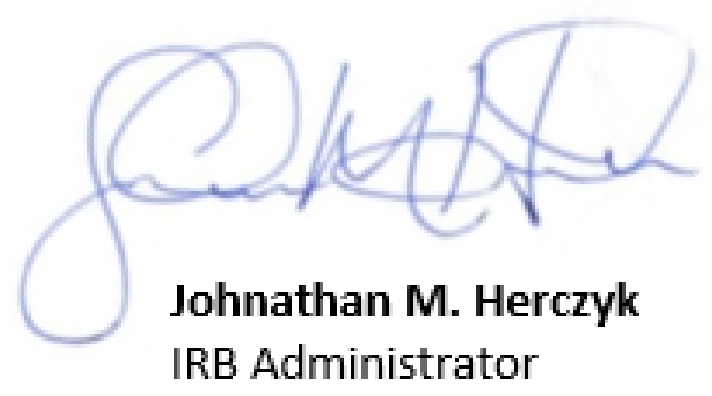

